\title{
The Questionnaire Analysis on University Counselor Specialized Development
}

\author{
Wang Jin $^{1}$ Zhu Yu ${ }^{2}$ Yang Yuanyan ${ }^{3}$ \\ ${ }^{1}$ Wang Jin (The school of Foreign Language, Wuhan Bioengineering Institute, Wuhan, Hubei) \\ ${ }^{2} \mathrm{Zhu} \mathrm{Yu}$ (The school of Foreign Language, Wuhan Bioengineering Institute, Wuhan, Hubei) \\ ${ }^{3}$ Yang Yuanyan (Personnel Department, Guilin College of Aerospace Technology, Guilin, Guangxi)
}

\begin{abstract}
This paper starts from the questionnaire on the specialized development of university counselor, which is to understand the needs of counselors in five aspects, such as specialization requirements, counselors' own training needs, occupational psychology and adjustment, counselor competency standards and improving methods, and the demand for professional title evaluation. Based on the findings, this paper proposes relevant measures on improving the specialized, scientific and professional development for university counselor.
\end{abstract}

\section{Keywords:}

Full-time counselor, Specialization, Capacity Building

The specialized development of university counselor has become the trend of teacher training reform. As one group of young teachers, full-time counselors' professional development is becoming increasingly valued.

\section{Survey Content}

By means of random sampling, the research group selected counselors in four universities nationwide (Shanghai Lixin Accounting University, Guilin University of Electronic Technology, Shunde Polytechnic College and Guilin College of Aerospace Technology). A total of 80 questionnaires was returned with 76 valid questionnaires. The effective rate was $95 \%$. The survey involves gender, age, working hours engaged in the work of counselors, major categories, etc. Among the respondents, the male counselors account for $30 \%, 70 \%$ are female counselors; under 28 years of age account for $47 \%$ of counselors, counselors aged 28-33 account for 48\%, 33 years or older account for $5 \%$ of counselors; under one year of working hours engaged in the work of counselor account for $32 \%, 1-3$ years working time account for $36 \%, 3$ years or above account for $32 \%$; counselors with arts major account for $56 \%$, science major counselors account for $12 \%$,

\begin{tabular}{|c|c|c|}
\hline \multirow{2}{*}{ gender } & Male & percentage \\
\cline { 2 - 3 } & Female & $30 \%$ \\
\hline \multirow{2}{*}{ age } & under 28 & $70 \%$ \\
\cline { 2 - 3 } & $28-33$ & $47 \%$ \\
\cline { 2 - 3 } in the work of & 33 or older & $48 \%$ \\
\cline { 2 - 3 } counselor & under 1year & $3 \%$ \\
\cline { 2 - 3 } working hours & $1-3$ years & $36 \%$ \\
\hline \multirow{2}{*}{$\begin{array}{c}\text { major } \\
\text { mears or above }\end{array}$} & $32 \%$ \\
\cline { 2 - 3 } category & arts & $56 \%$ \\
\cline { 2 - 3 } & science & $12 \%$ \\
\hline
\end{tabular}

engineering major account for $32 \%$ (see Fig. 1).

Fig. 1

The survey provides an effective, scientific basis for fully understanding the requirements and views of university counselors and help further analyze the causes and measures about teachers' moral accomplishment.

\section{Analysis of Survey Results}

The survey investigates counselors on issues about whether to build specialized counselors, how to promote the specialized development of counselors, the faculty training needs of their development, team building of full-time counselors and other aspects. 


\subsection{The specialized requirements of counselor development}

In the survey of the necessity of cultivating specialized counselors, $48.7 \%$ counselors believe it necessary to train specialized counselor personnel; $18.4 \%$ counselors think it doesn't matter because this profession is dispensable; and there are $32.9 \%$ of the counselors considering it is not necessary because counselors group need various professional people. It can be seen that most counselors endorse the creation of specialized counselors, and hope that this set of specialized training can build personnel with professional competence and professionalism. However, some counselors do not support specialized training in that counselor work is not targeted, technical and professional, and should be done by people of all majors in order to achieve major diversity.

In the survey about ways to improve counselor specialized development, $9 \%$ of the counselors are in line to create a good atmosphere for learning; $39 \%$ of the counselors think we should focus on improving the professional status of counselors; $8 \%$ of the counselors emphasize professional autonomy; and $44 \%$ of counselors view that a relaxed environment should be provided for the growth of specialization. It can be seen that more than half of counselors have relatively high requirements of the provided environment and status for professional growth, and they hope that the improvement of the external environment may help change the status of counselors.

In the survey on the existing problems in counselor specialized development, $42 \%$ of counselors are busy with daily affairs, and are lack of professional training; $34 \%$ counselors have multiple identities with role conflicting frequently; $16 \%$ think their academic status is not prominent, and feel low self-efficacy; and 8\% counselors regard their theoretical level as a problem. Thus it can be seen that counselors disagree with complexity of their own work and multiplicity of identities, hoping take clear responsibilities rather than multiple roles which is not conducive to counselor team-building and development.

\subsection{The faculty training of counselor development}

In the survey on whether to participate in faculty training, $49 \%$ of counselors participate in short-term trainings which are less than a month; $37 \%$ of people have never participated in any form of training; $11 \%$ participate in trainings which are less than one year; only $3 \%$ of people attend more than one year trainings.

In terms of the training content, 55\% feel the need of counseling and career planning; $17 \%$ believe that they need to create counselor workshop to strengthen the exchange and communication among counselors; $16 \%$ hope through management system to establish and improve school-based training system. That shows there is an increasing emphasis on individual career planning among counselors and they hope that university can provide a platform to give them guidance in direction and goals for their personal future development.

As for the choice of career planning, $42 \%$ of people hold the view that university should establish long-term training mechanism and assessment criteria; $33 \%$ of people think that university should determine the criteria of career planning and career development; $17 \%$ of people think that university should promote the professional disciplines of counselors.

In the opinion of main problems of counselor team building, $45 \%$ hold the idea that unstable team is the biggest problem; while $24 \%$ of people attribute to less learning and training and low overall academic level. It can be seen, in their own development process, counselors hope to increase the training opportunities to improve the individual overall quality. University should use various ways including sentiments, pay and career advancement opportunities to keep counselors to retain and expand their team building and finally raise the overall level of counselor team.

\subsection{Counselor psychological adjustment}

In the survey of counselor burnout psychology, there are $61 \%$ of counselors occasionally being mental burnout, and the longer they work, the more obvious the weary psychology is; $21 \%$ of them say it happens often; only $11 \%$ say never. Causes of the burnout psychology mainly come from the insufficient attention from university, for $29 \%$ of people attribute reasons to the profession itself, and $13 \%$ of them consider it out of the insufficient social concern. It can be seen, school and social attention and counselors' own recognition affect the cultivation of counselor professional psychology. 


\subsection{Counselor competency standards and improving methods}

It can be seen, through surveys, 57\% counselors think that language expression and organizational management skills are the capacity counselors should possess, and communication skills and lifelong learning should also be the capacity on the specialization of counselors. Most of the counselors hope through faculty training and academic and scientific research activities to increase the personal competence. Counselor work is a job that requires constant communication and expression, so the needs on language expression and organizational capacity are out of their own capacity requirements. They make an endeavor through the concept of lifelong learning to establish constant learning, and according to Peter Senge's proposed Discipline of self-transcendence, improving mental models, shared vision, team learning, and systems thinking, they constantly try to improve and perfect themselves.

\subsection{Counselor title evaluation}

In view of the current counselors' treatment and titles, $40 \%$ people consider unreasonable, hoping to improve; $28 \%$ of them appeal for setting up professional standards; $45 \%$ counselors wish to produce the flexible and open principle and clear assessment criteria on title evaluation. It can be seen that counselors want to enhance the personal qualities not only by the way of training, academic exchanges, and capacity building, but also through the titles evaluation to enhance personal cultivation. The counselor professional titles should be assessed according to the actual circumstance of counselor work, and through flexible and open principles, clear assessment standards, quantitative evaluation criteria, so as to promote of counselors' dedication in work, and achieve the progress in self-title improvement and capacity development.

\section{Measures to Improve Counselor Specialized Development}

\subsection{Establishing specialized counselor organization}

Because of counselors choosing to take the path of specialization, there must be appropriate evaluation criteria which requires specialized agencies to judge counselors and regularly request for evaluation in professional standards, professional ethics, and professional responsibilities. Therefore, the establishment of an authoritative and influential counselor professional association is imperative. Additionally, we need to establish counselor specialized training institution, relying on the professional training base. Currently, the Ministry of Education is actively exploring to build a nationwide counselor training base. This agency should also shoulder the role of building a lively communication platform for counselors. By conducting academic lectures, academic salon, reports and lectures and other forms of activities, it will encourage counselors to pursue advanced studies, with its aims to cultivate new talents with broad knowledge, strong adaptability, innovative spirit and international vision.

\subsection{Founding the corresponding specialized subject}

From the survey, we can find counselors have doubts for their work, and they rely solely on the subjective experiences and their own imagination to solve practical problems, no theoretical backing. So the establishment of student affairs administration subject is imperative. Independent discipline training mode can better guarantee the quality of counselors. In the short term, the subject for university counselors can be used as direction of discipline development; in the long term, it is conductive to the cultivation of high-level counselors.

\subsection{Combining pre-service short-term training and post-career long-term training}

Training is the inevitable choice of improving the quality of counselor team, and it should be combined pre-service short-term training with post-career long-term training together. Firstly, for daily, non professional work, the short-term training and experience exchange can directly provide the methods and skills to solve the problem, and improve the work efficiency of counselors. Secondly, intellectual skills education and the long-term training can offer psychological counseling, career guidance, student financial assistance and other specialized training to equip them with the skills and methods to solve professional problems and the ability to independently 
engage in students management to provide specialized services for students. For the work not requiring specialized knowledge and skills, for example, checking the student's schooling, checking the student dormitories and health, statistical information on students and some routine affairs, the pre-service training can guide them to understand the problem-solving process; while the students' confusion on psychological problems, employment, and personal life, it is necessary for counselors to receive post-career training on psychological knowledge, career guidance and other aspects of the relevant certification.

\subsection{Creating counselor team evaluation mechanism}

According to the nature of counselor work, the assessment of counselors should include: counselor ideological and theoretical level, realistic and pragmatic and pioneering spirit, performance of job duties, the actual effectiveness and other aspects. The assessment methods should adhere to the combination of qualitative evaluation and quantitative evaluation; the combination of self-assessment, department assessment, school assessment and student evaluation; the combination of inspection, sampling, competitions, statistics and surveys. Assessment results should link to benefits, rewards and punishments in university, the training opportunities and competitive employment. In an effort to achieve standardized, scientific and institutionalized assessment, university should also regularly analyze and summarize counselors' problems during the assessment, and establish relevant incentives to incline to counselors.

\subsection{Doing career planning}

Since counselors are mostly newly-graduates, they do not clearly recognize their working school, teaching work and their value. Therefore, university can establish the tutor system, create a good atmosphere of "mentoring", and provide research opportunities for counselors to improve their academic literacy. Through the formation of research teams or inter-institutional, interdisciplinary team building, and doing joint projects with the social enterprises, university should provide a platform and social assistance for counselors to do scientific research.

\section{Conclusion}

Specialization of university counselor is the key to teachers' professional development, and the trend in Chinese teachers' development and education, and the requirements and direction of promoting popularization of higher education. In our country's teacher education, there is a gap between counselor specialized training, the modern education request to teachers and the requirements of teacher profession for practitioners. To sum up, the research on counselor specialized development is conducive to the stabilization of counselors to gain professional status and rights. It can help promote the quality of overall counselor team, improve the counselors' teaching knowledge and skills, and increase the counselors' teaching level.

\section{References}

[1] Pang Xinpei, “Analysis of College Counselor Development Mechanism Based on 360-degree Feedback Evaluation," Journal of Zhejiang University of Technology (Social Science), pp. 184-185, 2008(6).

[2] Pang Xinpei, "Competency-based Research on Professional Development of College Counselor," Liaoning Education Research, pp. 92-94, 2008(9).

[3] Wang Baoyi, "On Specialization of College Counselor from Developmental Guidance Perspective," Ideological and Political Education Research, pp. 113-114, 2009(2).

[4] Wang Peijun, “College Counselor Capacity Development from the View of Specialization," Jiangsu Higher Education, pp. 108, 2009(3).

[5] Zhang Qiuhui, Wang Wenya, "On the Target System of College Counselors Professional Development," Journal of Jilin Institute of Socialism, pp. 43, 2008(4). 